\title{
A EDUCAÇÃO COMO MEIO DE TRANSFORMAÇÃO SOCIAL: O PROJETO ARQUITETOS DO SABER
}

Tatiane Almeida Netto ${ }^{1}$

Letícia Fátima de Azevedo²

Letícia Paludo Vargas ${ }^{3}$

Clayton Hillig ${ }^{4}$

Resumo: $O$ presente estudo traz como temática as ações de educação ambiental desenvolvidas no Projeto Arquitetos do Saber, vinculado ao projeto institucional da Universidade Federal de Santa Maria (UFSM) e financiado pelo edital Novos Talentos da Coordenação de Aperfeiçoamento de Pessoal de Nível Superior (Capes) do ano de 2010. As ações do projeto foram realizadas na Escola Estadual de Ensino Fundamental Dr. Honorato de Souza Santos, em Cachoeira do Sul, RS, nos anos de 2011 e 2012, envolvendo estudantes da faixa etária entre seis a doze anos, e teve como objetivo central a aproximação da escola básica ao ensino superior, proposta esta definida pelo edital da Capes. Para isso, serão abordados os conceitos que vincularam as ações do projeto, tais como: educação, educomunicação e Agroecologia.

Palavras-chave: Ações de Extensão; Educação Ambiental; Transformação.

\footnotetext{
${ }^{1}$ Universidade Federal de Santa Maria (UFSM). E-mail: tatianetto@gmail.com

2 Instituto de Desenvolvimento Educacional do Alto Uruguai, Bagé, RS. E-mail: letipvargas@gmail.com

${ }^{3}$ Universidade Federal de Santa Maria (UFSM). E-mail: letiazevedo@hotmail.com

${ }^{4}$ Universidade Federal de Santa Maria (UFSM). E-mail: hillig@smail.ufsm.br
} 


\section{Introdução}

O presente artigo traz como tema as ações de educação ambiental desenvolvidas no Projeto Arquitetos do Saber, vinculado ao projeto institucional da Universidade Federal de Santa Maria (UFSM) e financiado pelo edital Novos Talentos da Coordenação de Aperfeiçoamento de Pessoal de Nível Superior (Capes), 2010.

Ao visualizarmos o projeto Arquitetos do Saber, ampliamos o termo de educação ambiental, aliando ele a ciência da Agroecologia em busca de uma transformação social. A educação ambiental desenvolvida neste projeto pode ser comparada a uma modalidade de ensinar, devido a sua capacidade de informar, conscientizar e possibilitar a construção de cidadania e de autonomia dos sujeitos envolvidos nas ações.

As atividades do projeto se desenvolveram na Escola Estadual de Ensino Fundamental Dr. Honorato de Souza Santos, na Localidade de Passo D'Areia em Cachoeira do Sul, RS, nos anos de 2011 e 2012, envolvendo estudantes da faixa etária entre seis a doze anos, e teve como objetivo central a aproximação da escola básica ao ensino superior, proposta definida pelo edital da Capes e cumprida pelas práticas de educação ambiental desenvolvidas na escola, na UFSM e em parceiros do projeto engajados na temática da transformação social a partir da educação ambiental.

O Arquitetos do Saber divide suas ações em três eixos: cidadania, meio ambiente e Agroecologia. Embora ocorra esta divisão no papel, na prática as ações se complementam, visto que, a educação ambiental que se propõe é uma educação crítica e transformadora ancorada numa visão sistêmica de mundo.

Além da perspectiva de educação ambiental desenvolvida no Arquitetos do Saber, utiliza-se também o conceito de educação popular nas práticas realizadas, pelo fato de ser uma escola rural onde a democratização do saber e a emancipação social são o centro das ações. Vincula-se a educação ambiental também a ciência da educação do campo para a construção de uma educação popular, onde segundo Arroyo (2007) os vínculos entre território, terra, lugar e escola contribuem preponderantemente com a formação social, política, cultural e a identidade dos povos do campo. Com isso, neste artigo serão abordados os conceitos que vincularam as ações do projeto, são eles: a educação, a educomunicação e a Agroecologia.

A educação está voltada a ação e meio do desenvolvimento, seja no âmbito ambiental, do campo ou popular. A educomunicação é trabalhada no projeto como a ponte de diálogo que permite a ação comunicativa e a transformação social. E, a Agroecologia, ciência que transcende as teorias dos eixos articulados no projeto visa a participação social, a construção da autonomia crítica e a conservação e preservação do meio ambiente. 


\section{A educação como perspectiva de desenvolvimento}

Diversas ações de educação permearam as atividades do projeto, baseada em uma educação ambiental crítica que se sustenta nos conceitos de educação popular e do campo enfatizando o espaço rural, a cultura e os saberes presentes.

A educação que se propõe é uma ação educativa, democrática e participativa, que exige dos atores envolvidos uma mudança de paradigmas e uma nova postura de trabalho baseada em técnicas e métodos que estimulem a participação.

Falta na educação, de uma maneira geral, tanto nas universidades quanto no ensino básico, transpor a interdisciplinaridade alcançando a transdisciplinaridade, superando a fragmentação da realidade e promovendo as conexões, para recompor o conhecimento como um todo, compreendendo a educação como um procedimento social, humanitário e sistêmico.

A educação ambiental tem como perspectiva a produção do conhecimento a partir das relações socioambientais impostas pelo desenvolvimento, que atualmente está voltado à sustentabilidade ambiental, que prima não exclusivamente pelo ambiental, mas pelo social, político, econômico, ético e cultural (JACOBI, 2003). O autor ainda propõe ser necessária uma "reflexão sobre os desafios para mudar as formas de pensar e agir em torno da questão ambiental numa perspectiva contemporânea" (JACOBI, 2003 p.190).

No que se refere à educação popular, o trabalho educativo neste âmbito deve ser desenvolvido através de uma ação transformadora que visa formar os sujeitos críticos na realidade em que estão inseridos e, ainda, está centrada em três vertentes principais, são elas: ação cultural, movimento de educação popular e teoria de educação (PALUDO, 2012).

No que diz respeito à educação do campo, pode-se dizer que é uma prática social associada a uma consciência de mudança, destinada a moradores do campo, relacionada à cultura, valores, maneira de produzir, permeando a participação dos sujeitos (CALDART, 2012).

A educação do campo ainda pode ser definida como "[...] superação: projeto/utopia: projeção de uma outra concepção de campo, de sociedade, de relação campo e cidade, de educação, de escola. Perspectiva de transformação social e de emancipação humana" (CALDART, 2004 p.67).

Além disso, a especificidade do campo emerge a necessidade de uma educação associada à produção da vida, do conhecimento e da cultura do campo, apontando ações e desafios para trabalhar o modo de vida da comunidade em torno da escola.

No documento "Referências para uma Política Nacional de Educação do Campo", que subsidia reivindicações para ações públicas estatais quanto à educação do campo, fica evidente que:

revista brasileira educação ambiental 
[...] Uma Política Pública de Educação do Campo deve respeitar todas as formas e modalidades de educação que se orientem pela existência do campo como um espaço de vida e de relações vividas, porque considera o campo como um espaço que é ao mesmo tempo produto e produtor de cultura (BRASIL, 2003, p.31).

Considerando as atividades práticas desenvolvidas pelo projeto, pode-se destacar que em relação à educação ambiental, popular e do campo, são enfatizadas as ações realizadas nos três eixos, que levam em consideração o saber popular, as tradições e a cultura local.

Uma das ações desenvolvidas no eixo meio ambiente é a oficina de plantas medicinais (Figura 1), com atividades teóricas e práticas, resgatando a cultura e a tradição local. Primeiramente, foram expostas pelos monitores do projeto uma série de plantas medicinais, com fotos ilustrativas e a utilização das mesmas, afirmando a importância do uso correto e do conhecimento da posologia de cada planta.

Posteriormente, foi realizada a visitação na casa da mãe de um dos estudantes, para possibilitar a interação entre a comunidade escolar, onde a mãe explicou sobre as plantas medicinais existentes na residência, como deve ser realizado o plantio e para que devem ser utilizadas. Por fim, foi realizada a degustação dos chás, para o maior contato com o objeto de estudo.

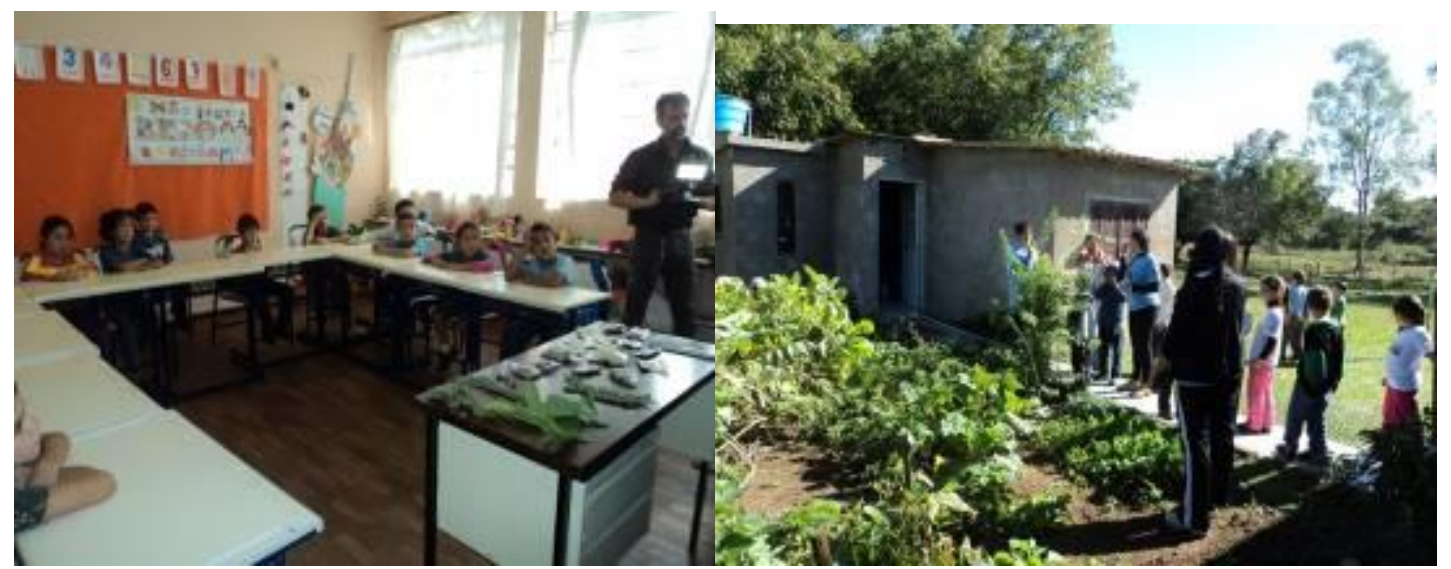

Figura 1: Oficina de plantas medicinais.

Fonte: Acervo dos autores (2012). 


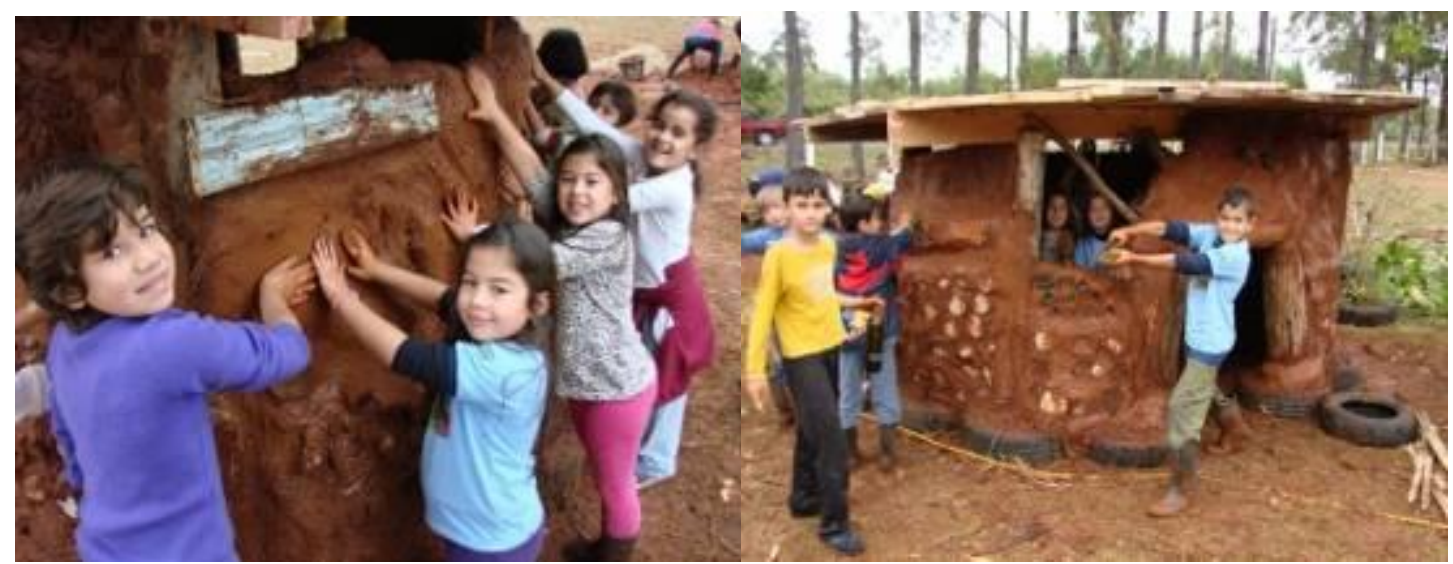

Figura 2: Oficina Bioconstrução.

Fonte: Acervo dos autores (2012).

Por fim, no eixo cidadania destacam-se ações de construção de autonomia dos sujeitos na comunidade, como por exemplo, na oficina de resgate histórico e cultural, realizada na Escola Honorato, onde os estudantes fizeram uma coleta de fotos e histórias antigas ligadas ao contexto escolar, em comemoração aos setenta anos da escola, com o objetivo de construção da identidade local.

\section{O diálogo como ferramenta para a construção do saber}

As ações de educomunicação priorizam a relação entre a comunidade escolar e monitores, criando novas possibilidades de resgate dos conhecimentos locais e de participação consciente nas mudanças necessárias nos níveis da sustentabilidade: dimensão política, social, ambiental, econômica, cultural e ética. A troca de saberes no projeto, estabelecida na participação e no diálogo, possibilitou a construção de conhecimento.

Entende-se como espaço educativo todo ambiente onde se promove a formação humana, e, como observou Paulo Freire (1979) educação é comunicação, onde a ação comunicativa está embasada no homem concreto, que não existe senão na realidade também concreta que o condiciona. Paulo Freire ao pensar a educação e a comunicação junto, aponta o caminho para uma demanda social.

O termo educomunicação surgiu inicialmente nos textos de Mario Kaplún, na década de 1970, para designar atividades de educação para a comunicação e leitura crítica dos meios. Freire, também na década de 1970

utilizava-se da teoria comunicativa, na medida em que vê a educação como um processo de comunicação. Para o autor, a educação ajuda a ler o mundo, a ler a comunicação que existe sobre o mundo, a produzir comunicação sobre o mundo e a produzir o mundo (SOARES, 2000; FREIRE, 1975). 
Educomunicação, de acordo com o Núcleo de Comunicação e Educação $(\mathrm{NCE})^{4}$, conceitua-se como um conjunto das ações inerentes ao planejamento, implementação e avaliação de processos, programas e produtos, destinados a criar e a fortalecer ecossistemas comunicativos abertos, democráticos e participativos, e a ampliar os espaços de expressão na sociedade através de uma gestão democrática dos recursos da comunicação (SOARES, 2009).

Assim, num contexto dialético do exercício do diálogo com o outro pessoal e institucional - propõe-se que o conceito da Educomunicação seja usado para promover articulações coletivas, multiculturais e midiáticas em função do uso dos processos e ferramentas da comunicação em proveito da construção, tanto dos indivíduos como das comunidades (SOARES, 2009).

A interrelação entre comunicação e educação é consolidada como um novo campo de intervenção social e de atuação profissional, considerando que a informação é um fator fundamental para a Educação (FÓRUM MÍDIA \& EDUCAÇAึ̊, 2000).

O espaço mediático ${ }^{5}$ é um espaço educativo, e, portanto, a sua leitura crítica e cidadã pressupõe refletir e sistematizar informações que possibilitem um maior esclarecimento sobre as demandas da sociedade constituindo-se em um espaço público e político privilegiado da atualidade (FÓRUM MÍDIA \& EDUCAÇÃO, 2000, p.21).

Todas as ações desenvolvidas pelo Projeto têm como base os princípios da educomunicação, voltadas ao diálogo e à ação comunicativa. A ação comunicativa leva em consideração que o homem não reage simplesmente a estímulos do meio, mas atribui um sentido às suas ações e, graças à linguagem, é capaz de comunicar percepções e desejos. Habermas vislumbra a possibilidade de que, através do diálogo o homem possa retomar o seu papel de sujeito (GONÇALVES, 1999).

As oficinas desenvolvidas nos três eixos priorizaram o diálogo na construção do conhecimento, levando em consideração o modo de vida dos estudantes. A oficina de fauna e flora, desenvolvida pelos monitores teve como objetivo analisar os conhecimentos prévios dos estudantes em relação às espécies animais e vegetais da região, bem como informá-los da importância da preservação da fauna e flora local.

Durante a realização da atividade, os estudantes visitaram um orquidário em Cachoeira do Sul (RS), o Criadouro Conservacionista São Braz (Figura 3) e a Mostra de Biologia na UFSM, em Santa Maria (RS).

\footnotetext{
${ }^{4}$ O Núcleo de Comunicação e Educação (NCE) nasceu em 1996 reunindo um grupo de professores de várias universidades brasileiras interessadas na inter-relação entre Comunicação e Educação. Disponível em: http://www.usp.br/nce/onucleo/

${ }^{5}$ Mediatização está associada à idéia de mediação proposta por Martín-Barbéro (1996), que percebe os meios de comunicação para além da condição de canal, mídia, e entende que, antes de tudo, estes meios de comunicação são elementos reguladores das relações sociais e estão na própria base da constituição dessas relações.
} 


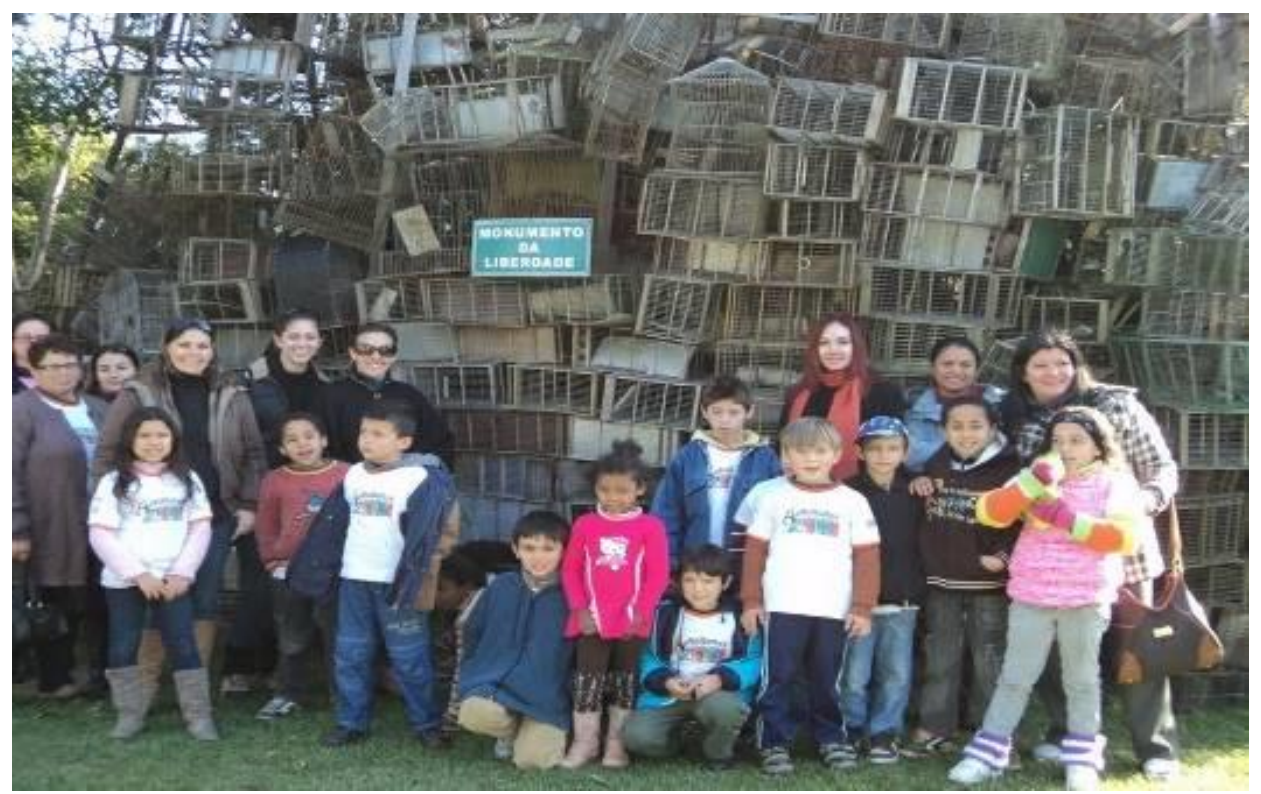

Figura 3: Oficina de educação ambiental: Visita Criatório Conservacionista São Brás, Santa Maria (RS). Fonte: Acervo dos autores (2011).

Além destas, outras ações estimularam a educação e comunicação dos estudantes, como por exemplo, a visita à Câmara de Vereadores em Cachoeira do Sul (RS) (Figura 4) e à Brigada Militar em Santa Maria (RS), que permitiram a vivência em uma realidade até então desconhecida para a maioria. As atividades propiciaram a formação da cidadania através da percepção das distintas realidades que podem ocorrer no contexto onde os mesmos estão inseridos.

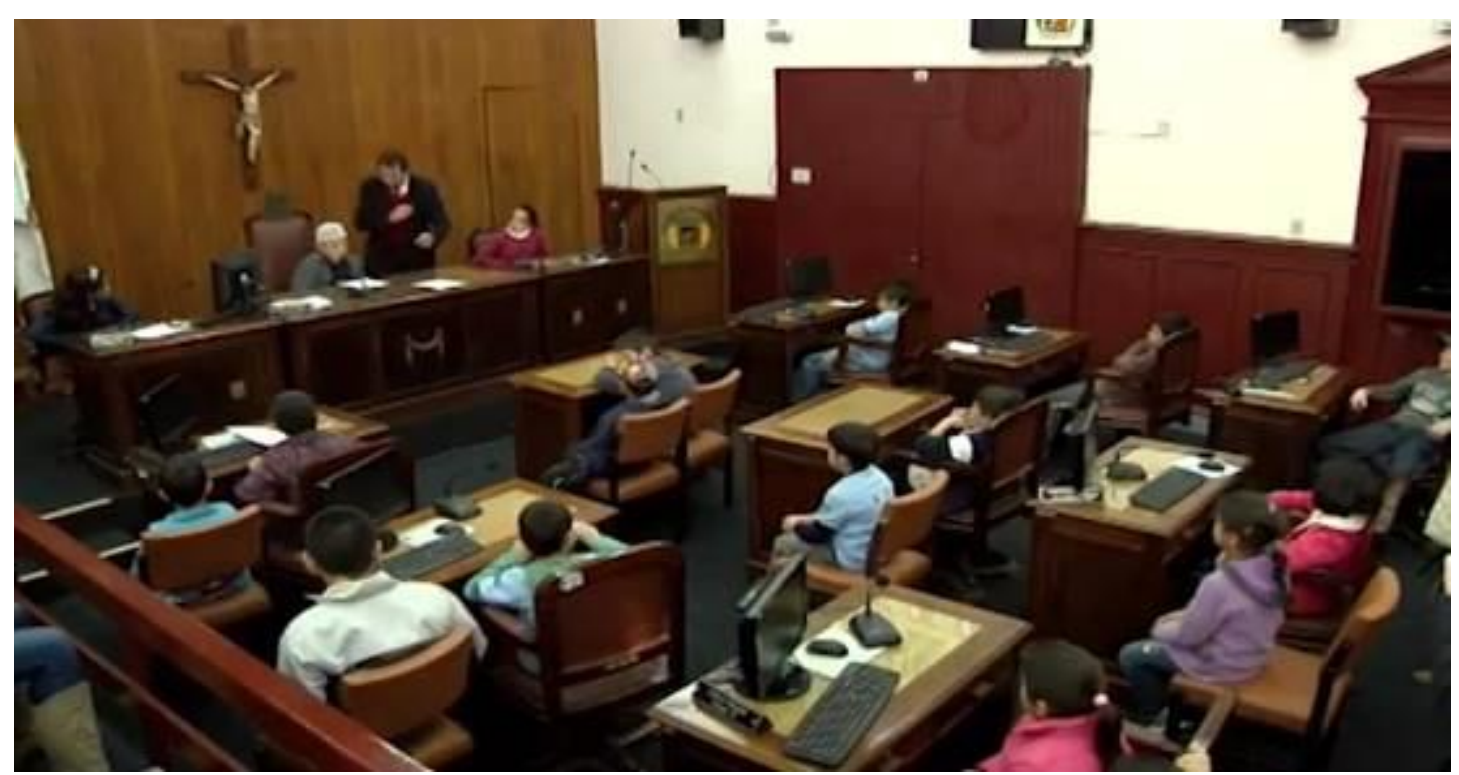

Figura 4: Oficina de cidadania: visita à Câmara de Vereadores de Cachoeira do Sul, RS.

Fonte: Acervo dos autores (2012). 


\section{A Agroecologia como perspectiva de transformação socioambiental}

As ações desenvolvidas junto à escola, direta ou indiretamente estavam fundamentadas em princípios Agroecológicos, na sustentabilidade ambiental, equidade social, saberes tradicionais, enfoque sistêmico e participação.

A Agroecologia tem um enfoque na agricultura, mais relacionado ao meio ambiente e mais sensível socialmente, busca a produção, mas também a sustentabilidade ecológica do sistema de produção que vai além da unidade de produção e abrange os ecossistemas.

A interação de características endógenas (biológicas e ambientais) e exógenas (sociais e econômicas) leva a uma estrutura particular de agroecossistema, podendo ser considerado o eixo central da Agroecologia (HECHT, 1999).

A autora destaca ainda que a Agroecologia é baseada em um enfoque que integra ideias e métodos de vários subcampos, e não apenas de uma disciplina específica e, tem suas raízes no movimento agrícola e ecologista, na análise de agroecossistemas indígenas e em estudos sobre desenvolvimento rural, possuindo metodologias distintas, que em conjunto influenciam o pensamento Agroecológico (HECHT, 1999).

Para Costa Gomes e Borba (2004), a Agroecologia representa um avanço paradigmático somente para aqueles que estão em busca do novo e a base epistemológica da Agroecologia incorpora a complexidade, a dúvida, a incerteza, e pretende ser inter ou transdisciplinar; sua pauta é a temática e não a disciplina, além de reconhecer os saberes tradicionais e cotidianos como também válidos.

Os autores também apontam a necessidade de uma revisão metodológica que incorpore as ciências sociais, na perspectiva de um pluralismo metodológico, permitindo superar a aplicação linear promovendo uma relação mais harmoniosa entre a sociedade e a natureza, pois o sujeito tem a capacidade de transformar e ser transformado pelo meio (COSTA GOMES; BORBA, 2004).

As análises da Agroecologia concentram esforços na dimensão comunitária em que se inserem os agricultores, isto é, a realidade sociocultural que proporciona uma práxis intelectual e política da identidade local e de sua rede de relações sociais. Isso requer amplas relações institucionais (públicas, privadas e do terceiro setor) para promover o sinergismo entre as políticas públicas, com vistas a obter soluções mais integrais ou mais ampliadas dos problemas.

Além disso, a Agroecologia pode ser medida pelas perspectivas epistemológicas, metodológicas, sociológicas e tecnológicas respectivamente pela conquista contra a ilusão do saber imediato, por uma construção teórica, por instrumento de empoderamento da sociedade e por uma comprovação empírica, o que demonstra sua multidimensionalidade na construção do conhecimento (COSTA GOMES; BORBA, 2004). 
Descrita por Leff (2002) como instrumento a favor do desenvolvimento sustentável, a Agroecologia se entrelaça nas experiências da agricultura ecológica em sua parte produtiva, para poder elaborar propostas de ação social coletiva, objetivando substituir o modelo considerado depredador por outro, voltado "para a construção de uma agricultura socialmente justa, economicamente viável e ecologicamente sustentável".

Por fim, pode-se dizer que é através da Agroecologia que podemos legitimar o desenvolvimento rural sustentável, buscando uma harmonia entre as diversas dimensões da sustentabilidade. Atuando dessa forma, como ciência ou disciplina científica, a Agroecologia busca a transição do atual modelo de desenvolvimento para um mais sustentável e equitativo, tendo como eixo central o reconhecimento do "saber" dos agricultores e de suas famílias, importando-se com seu lado social, cultural e não só com o lado econômico (produção e produtividade). A demanda por outro estilo ou modelo de agricultura deve incorporar princípios, métodos e tecnologias de base ecológica.

Uma das ações realizadas no contexto da Agroecologia foi a criação de uma horta vertical com plantio de temperos verdes e alfaces utilizados posteriormente na merenda escolar. Cada estudante ficou responsável pela manutenção de uma jardineira feita de garrafa pet e customizada por eles com pinturas. Esta horta tinha como objetivo a reutilização das garrafas plásticas, contribuindo para a reciclagem destes materiais e a possibilidade de mudança nos hábitos alimentares, contribuindo para a promoção da produção de alimentos livres de defensivos e insumos químicos, contextualizando desta forma um ambiente mais saudável, auxiliando na educação ambiental e de um pensamento sustentável. A horta vertical é uma modalidade que pode ser construída em pequenos espaços e proporciona o embelezamento da paisagem, conforme pode ser visto na Figura 5, a seguir.

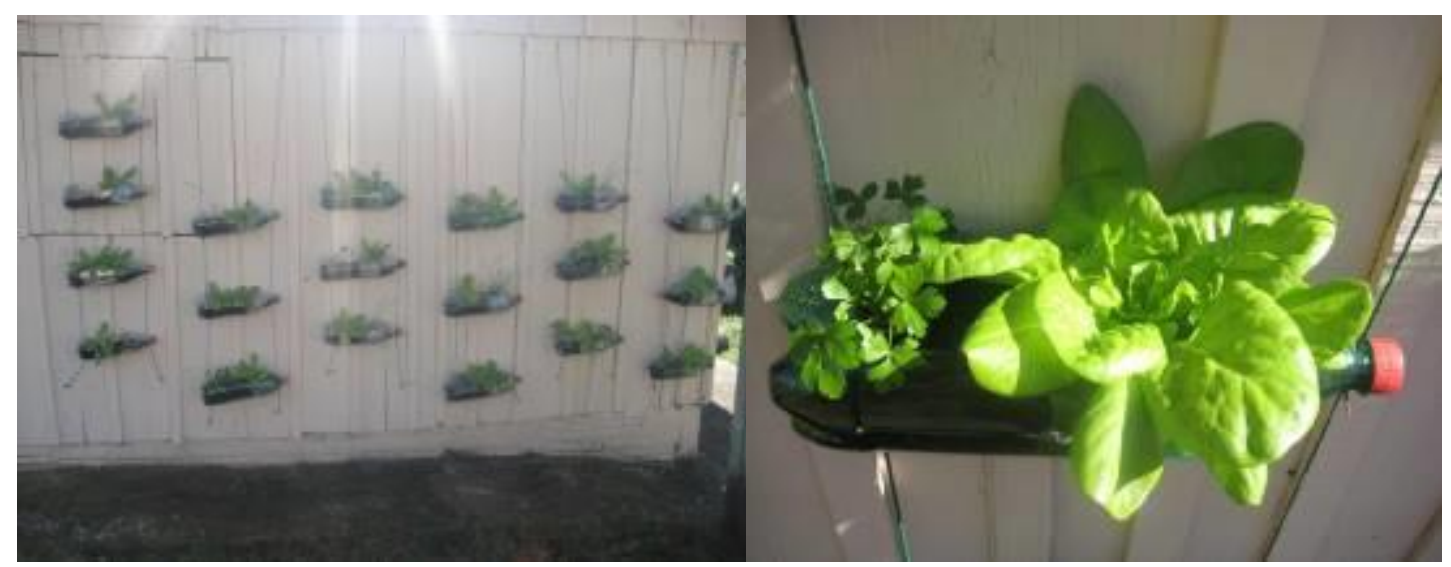

Figura 5: Horta vertical.

Fonte: Acervo dos autores (2012). 


\section{Considerações finais}

Diante das ações realizadas no Projeto Arquitetos do Saber, constatouse que os estudantes, através da participação nas mesmas, puderam crescer socialmente. As práticas permitiram o desenvolvimento de reflexões, característicos dos processos de comunicação, quando ocorre a participação ativa dos sujeitos e a valorização do saber local.

Como resultado, destaca-se a transformação social obtida na escola e na comunidade escolar. Além disso, o envolvimento dos estudantes, pais professores, funcionários e moradores da comunidade demonstram a coparticipação dos diferentes sujeitos envolvidos, atuando como protagonistas em propósito de (re)construção social.

O projeto proporcionou aos estudantes envolvidos uma nova vivência, uma transformação não só de saberes, mas a perspectiva de novos horizontes. A utilização de práticas como educação ambiental, cidadania e Agroecologia alicerçadas aos conceitos de educação do campo, popular, ambiental e educomunicação permitiu a troca de saberes, o diálogo e a aproximação entre os diferentes universos.

A integração dos aspectos sociais, ecológicos e culturais de uma educação do campo pode ser evidenciada no transcorrer do projeto, através de uma educação que enfatiza as especificidades do rural e dos seus sujeitos, com propósito de resgate dos valores culturais e de práticas que propiciam a construção da cidadania.

\section{Referências}

ARROYO, M.G. Políticas de formação de educadores(as) do campo. Cad. Cedes, Campinas, vol. 27, n. 72, p. 157-176, maio/ago. 2007.

BRASIL. Referências para uma Política Nacional de Educação do Campo. Caderno de subsídios. Brasília, outubro, 2003.

CALDART, R.S. Por uma educação do campo: traços de uma identidade em construção. In: ARROYO, M.G.; CALDART, R.; MOLINA, M. Por uma educação do campo. Petrópolis: Vozes, 2004.

CALDART, R.S. Educação do campo. CALDART, et al. (Orgs). Dicionário da Educação do Campo. São Paulo: Escola Politécnica de Saúde Joaquim Venâncio, Expressão Popular, 2012.

COSTA GOMES, J. C.; BORBA, M. Limites e possibilidades da Agroecologia como base para sociedades sustentáveis. Ciência \& Ambiente 29.Julho/Dezembro de 2004.

FÓRUM MÍDIA \& EDUCAÇÃO: Perspectivas para a qualidade da informação. Brasília, 2000. Disponível em: <http://www.unicef.org/bra zil/pt/midiaedu.pdf $>$. Acesso em: 20 nov.2014. 
FREIRE, P. Extensão ou Comunicação?2 Ed. Rio de Janeiro: Paz e Terra, 1975.

FREIRE, P. Educação como prática da liberdade. 17.ed. Rio de Janeiro: Paz e Terra, 1979.

GONÇALVES, M.A.S. Teoria da ação comunicativa de Habermas: Possibilidades de uma ação educativa de cunho interdisciplinar na escola. Educação \& Sociedade. Ano XX, n. 66, 1999.

HECHT, S.B. La evolución del pensamiento agroecológico. In: ALTIERI, M. A. Agroecologia: Bases científicas para una agricultura sustentable. Montevideo: Editorial Nordan-Comunidad. 1999.

JACOBI, P. Educação ambiental, cidadania e sustentabilidade. Cadernos de Pesquisa. n. 118, p. 189-205, 2003

LEFF, E. Agroecologia e saber ambiental. Revista Agroecologia e Desenvolvimento Rural Sustentável. Porto Alegre, v.3, n.1, jan./mar.2002.

MARTÍN-BARBÉRO, J. Dos meios às Mediações. Rio de Janeiro: Ed. UFRJ. 1996.

PALUDO, C. Educação Popular. In: CALDART, et al. (Orgs). Dicionário da Educação do Campo. São Paulo: Escola Politécnica de Saúde Joaquim Venâncio, Expressão Popular, 2012.

SOARES, I.O. Gestão comunicativa e educação: Caminhos da educomunicação. In: Comunicação \& Educação, São Paulo, ECA/USPEditora Segmento, Ano VIII, jan/abr. n. 23. 2000.

SOARES, I.O. Caminos de la educomunicación: utopías, confrontaciones, reconocimientos, in Nomadas, Universidad Cental, Bogotá, 2009, p.194-207. 